\title{
Differences in Medicaid Antipsychotic Medication Measures Among Children with SSI, Foster Care, and Income-Based Aid
}

\author{
Emily Leckman-Westin, PhD; Molly Finnerty, MD; Sarah Hudson Scholle, MPH, DrPH; \\ Riti Pritam, MA, MRP; Deborah Layman, MA; Edith Kealey, PhD; Sepheen Byron, MHS; \\ Emily Morden, MSW; Scott Bilder, PhD; Sheree Neese-Todd, MA; Sarah Horwitz, PhD; \\ Kimberly Hoagwood, PhD; and Stephen Crystal, PhD
}

\begin{abstract}
BACKGROUND: Concerns about antipsychotic prescribing for children, particularly those enrolled in Medicaid and with Supplemental Security Income (SSI), continue despite recent calls for selective use within established guidelines.

OBJECTIVES: To (a) examine the application of 6 quality measures for antipsychotic medication prescribing in children and adolescents receiving Medicaid and (b) understand distinctive patterns across eligibility categories in order to inform ongoing quality management efforts to support judicious antipsychotic use.

METHODS: Using data for 10 states from the 2008 Medicaid Analytic Extract (MAX), a cross-sectional assessment of 144,200 Medicaid beneficiaries aged $<21$ years who received antipsychotics was conducted to calculate the prevalence of 6 quality measures for antipsychotic medication management, which were developed in $2012-2014$ by the National Collaborative for Innovation in Quality Measurement. These measures addressed antipsychotic polypharmacy, higher-than-recommended doses of antipsychotics, use of psychosocial services before antipsychotic initiation, follow-up after initiation, baseline metabolic screening, and ongoing metabolic monitoring.
\end{abstract}

RESULTS: Compared with children eligble for income-based Medicaid, children receiving SSI and in foster care were twice as likely to receive higherthan-recommended doses of antipsychotics (adjusted odds ratio $[\mathrm{AOR}]=2.4$, $95 \% \mathrm{Cl}=2.3-2.6 ; \mathrm{AOR}=2.5,95 \% \mathrm{Cl}=2.4-2.6$, respectively) and multiple concurrent antipsychotic medications $(\mathrm{AOR}=2.2,95 \% \mathrm{Cl}=2.0-2.4$;

$\mathrm{AOR}=2.2,95 \% \mathrm{Cl}=2.0-2.4$, respectively). However, children receiving $\mathrm{SSI}$ and in foster care were more likely to have appropriate management, including psychosocial visits before initiating antipsychotic treatment and ongoing metabolic monitoring. While children in foster care were more likely to experience baseline metabolic screening, SSI children were no more likely than children eligible for income-based aid to receive baseline screening.

CONCLUSIONS: While indicators of overuse were more common in SSI and foster care groups, access to follow-up, metabolic monitoring, and psychosocial services was somewhat better for these children. However, substantial quality shortfalls existed for all groups, particularly metabolic screening and monitoring. Renewed efforts are needed to improve antipsychotic medication management for all children.

J Manag Care Spec Pharm. 2018;24(3):238-46

Copyright @ 2018, Academy of Managed Care Pharmacy. All rights reserved.

\section{What is already known about this subject}

Antipsychotic prescribing has become more common in children and adolescents.

There are broad concerns regarding the consequences of antipsychotic medication treatment for youth.

\section{What this study adds}

This study provides prevalence data for 6 quality measures regarding concerns associated with pediatric antipsychotic prescribing and compares these metrics across 3 aid categories for children enrolled in 10 state Medicaid programs.

Study results demonstrate the importance of ongoing quality monitoring and direct efforts to improve antipsychotic-related care processes among all subgroups of Medicaid youth.

丁 se of antipsychotic prescriptions, particularly in youth whose medical care is publicly funded, peaked in the mid to late 2000s before national attention and concerted quality improvement efforts supported a gradual decline of the overall use of antipsychotic prescriptions for children and adolescents. ${ }^{1-9}$ Children in foster care have been identified as particularly at risk: One study found that 45 states experienced an increase in the number of children in foster care on antipsychotics between 2002 and 2007, with increases ranging from $71.9 \%$ to $6.4 \%$ and a median increase of $12.8 \% .^{10}$

Although well-monitored antipsychotic prescription use has a place in the treatment of certain symptoms and disorders, recent work has documented that a majority of children were prescribed antipsychotics for off-label use. ${ }^{11,12}$ Most use of antipsychotics in children and adolescents is for behavioral conditions for which psychotherapy and other nonmedication treatments are recommended as the first line of therapy. ${ }^{12-15}$ Moreover, there is evidence that children and adolescents, particularly those in foster care, do not receive first-line psychotherapy before initiation of antipsychotics nor do they receive adequate health monitoring, indicating the ongoing need for improvement in treatment quality and clinical decision making. ${ }^{16}$

As the use of medications has increased, so has the evidence for potential adverse consequences of antipsychotic use. Antipsychotics, and second-generation antipsychotics in particular, are associated with diabetes and obesity, ${ }^{17,18}$ but 
Differences in Medicaid Antipsychotic Medication Measures Among Children with SSI, Foster Care, and Income-Based Aid

\section{FIGURE 1 Understanding Measure Definitions: Continuous Medicaid Eligibility Requirements and Other} Inclusion/Exclusion Criteria

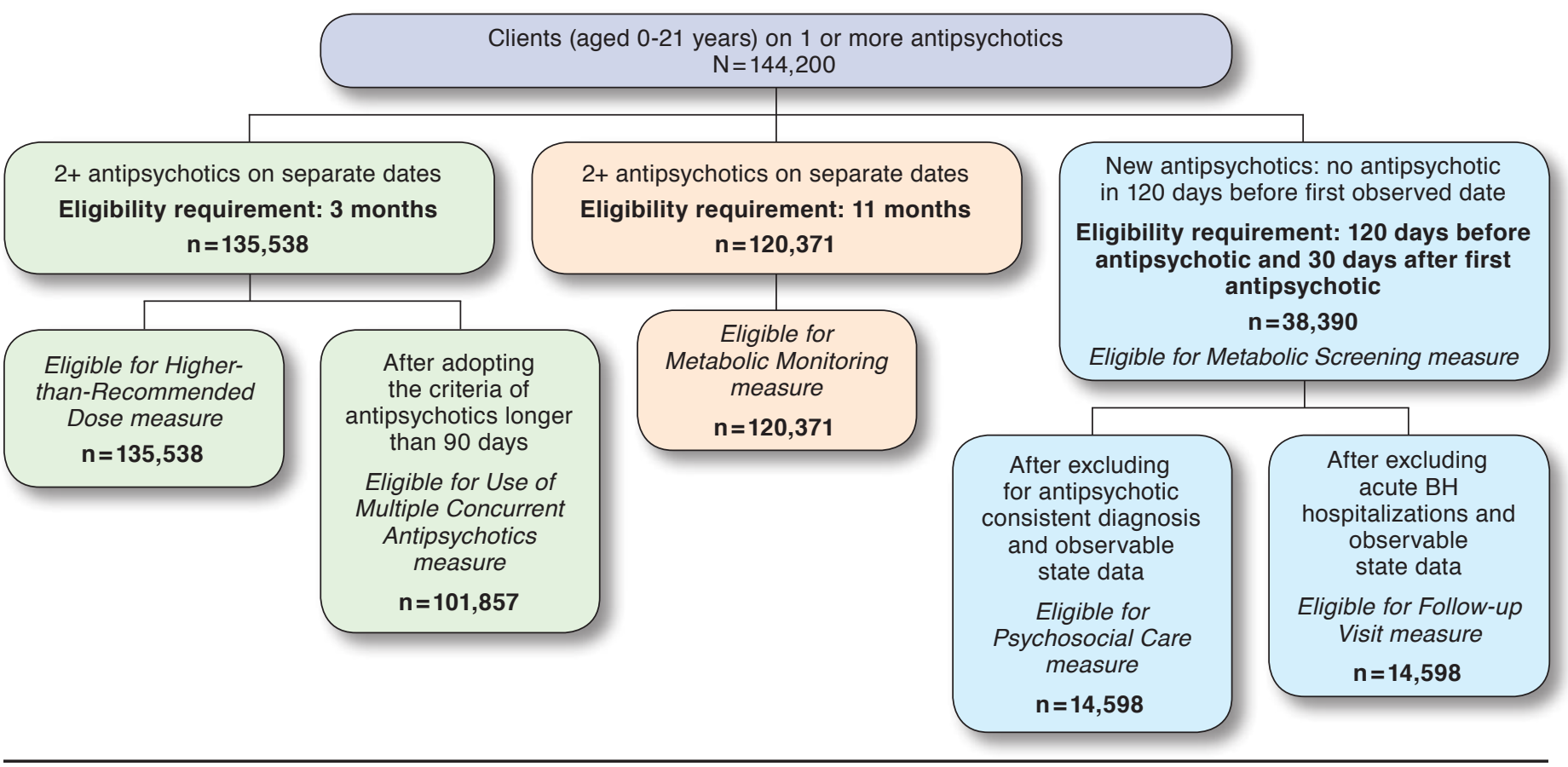

BH= behavioral health

screening for potential metabolic concerns is low for individuals starting antipsychotics. ${ }^{19,20}$ Specifically, screening for individuals starting antipsychotics range from $10 \%$ to $28 \%$, depending on the age and/or agent. ${ }^{17,18}$ In fact, the metabolic consequences of antipsychotics may present faster in children and adolescents. ${ }^{21-23}$ Such concerns have led to increased scrutiny of antipsychotic use in children, particularly children in foster care. ${ }^{7,8,10,15,24,25}$ Between 1997 and 2006, evidence from 1 midAtlantic state suggests that the prevalence of antipsychotic use by children receiving Supplemental Security Income (SSI; $5.8 \%$ on antipsychotics) resembles the rates seen in studies of youth in foster care (4.4\% on antipsychotics). ${ }^{8}$ During this same period, the number of children eligible for antipsychotics because of mental disorders has significantly increased to represent almost half of all children receiving SSI, but the patterns of potentially questionable antipsychotic prescribing in this population are largely unknown. ${ }^{26-28}$

There is an ongoing need for information on quality of care related to antipsychotic use in children enrolled in Medicaid and Medicaid managed care plans. We examined a new suite of performance measures that assess safe and judicious use of antipsychotics. These measures were developed from 20122014 by the National Collaborative for Innovation in Quality Measurement (NCINQ), a center of excellence funded under the Agency for Healthcare Research and Quality/Centers for
Medicare \& Medicaid Services Pediatric Quality Measures Program. ${ }^{29}$ NCINQ included investigators from New York University; Nationwide Children's Hospital; New York State Office of Mental Health; and the Rutgers Center for Health Services Research on Pharmacotherapy, Chronic Disease Management, and Outcomes, under the leadership of the National Committee for Quality Assurance, to prioritize, develop, test, and build on quality measures related to antipsychotic use in children. ${ }^{25,30}$ Measure selection and refinement was informed by guideline review ${ }^{31}$; extensive stakeholder consultation, including pediatricians; and measure testing. Using the NCINQ measures, we compared the quality of care for children by type of Medicaid eligibility program. In particular, we compared the antipsychotic measures for children enrolled in SSI, foster care, and income eligibility categories in order to understand the extent of potentially questionable antipsychotic prescribing in Medicaid-enrolled children.

\section{Methods}

\section{Study Population}

The 2008 Medicaid Analytic Extract (MAX) data for 10 states were used to identify children on antipsychotics during 2008. MAX files comprise an annual database of Medicaid enrollment, service utilization, and expenditure data and were used to construct enrollment, diagnosis, and treatment histories 
TABLE 1 Quality Measures for Antipsychotic Medication Management

\begin{tabular}{|c|c|c|c|}
\hline Measure Name & Denominator & Numerator & Rationale $^{a}$ \\
\hline \multicolumn{4}{|c|}{ Appropriate Use of Antipsychotics (Lower rates indicate better performance) } \\
\hline $\begin{array}{l}\text { Use of Higher-than-Recommended } \\
\text { Doses of Antipsychotics in Children } \\
\text { and Adolescents }\end{array}$ & $\begin{array}{l}\text { Prescribed antipsychotics (same or } \\
\text { different drug on } 2 \text { or more dates) }\end{array}$ & $\begin{array}{l}\text { Antipsychotic prescriptions with } \\
\text { higher-than -recommended doses }\end{array}$ & $\begin{array}{l}\text { Guidelines endorse conservative } \\
\text { dosing strategies for children, noting } \\
\text { dosing should start low and, if needed, } \\
\text { be increased over time. }\end{array}$ \\
\hline $\begin{array}{l}\text { Use of Multiple Concurrent } \\
\text { Antipsychotics in Children and } \\
\text { Adolescents }\end{array}$ & $\begin{array}{l}\text { Continuous antipsychotic treat- } \\
\text { ment prescribed } 90 \text { days or longer }\end{array}$ & $\begin{array}{l}2 \text { or more concurrent antipsychotic } \\
\text { trials for longer than } 90 \text { days }\end{array}$ & $\begin{array}{l}\text { Guidelines state the concurrent use of } 2 \\
\text { or more antipsychotics should be avoided } \\
\text { except when transitioning from } 1 \text { medica- } \\
\text { tion to another. }\end{array}$ \\
\hline \multicolumn{4}{|c|}{ Management of Youth on Antipsychotics (Higher rates indicate better performance) } \\
\hline $\begin{array}{l}\text { Use of First-Line Psychosocial Care } \\
\text { for Children and Adolescents on } \\
\text { Antipsychotics }\end{array}$ & $\begin{array}{l}\text { New prescription of antipsychotics } \\
\text { without a primary indication }\end{array}$ & $\begin{array}{l}\text { A psychosocial visit } 90 \text { days before } \\
\text { or within } 30 \text { days after the new } \\
\text { antipsychotic prescription }\end{array}$ & $\begin{array}{l}\text { For children without a primary indica- } \\
\text { tion, guidelines recommend psycho- } \\
\text { social treatment before antipsychotics. } \\
\text { Guidelines specifically recommend psy- } \\
\text { chosocial services as first-line treatment } \\
\text { for those with aggression or disruptive } \\
\text { behavior disorders. }\end{array}$ \\
\hline $\begin{array}{l}\text { Follow-Up Visit for Children and } \\
\text { Adolescents on Antipsychotics }\end{array}$ & New prescription of antipsychotics & $\begin{array}{l}\text { A follow-up care visit with a } \\
\text { prescriber within } 30 \text { days after the } \\
\text { new antipsychotic prescription }\end{array}$ & $\begin{array}{l}\text { Guidelines support follow-up with a } \\
\text { prescriber for children on antipsychotics, } \\
\text { noting that visit frequency depends on } \\
\text { severity of illness and the need to moni- } \\
\text { tor symptoms and side effects. }\end{array}$ \\
\hline $\begin{array}{l}\text { Metabolic Screening for Children and } \\
\text { Adolescents Newly on Antipsychotics }\end{array}$ & New prescription of antipsychotics & $\begin{array}{l}\text { Blood glucose and lipid screening } \\
\text { within } 90 \text { days before or within } \\
15 \text { days after the new antipsychotic } \\
\text { prescription }\end{array}$ & $\begin{array}{l}\text { Guidelines recommend baseline meta- } \\
\text { bolic screening of children on antipsy- } \\
\text { chotics, with most specifying glucose and } \\
\text { lipid screening at a minimum. }\end{array}$ \\
\hline $\begin{array}{l}\text { Metabolic Monitoring for Children } \\
\text { and Adolescents on Antipsychotics }\end{array}$ & $\begin{array}{l}\text { Prescribed } 2 \text { or more antipsychot- } \\
\text { ics (same or different drug) on dif- } \\
\text { ferent dates of service }\end{array}$ & $\begin{array}{l}\text { Blood glucose and lipid testing } \\
\text { during the measurement year }\end{array}$ & $\begin{array}{l}\text { While the specific tests called for and } \\
\text { frequency of monitoring varied across } \\
\text { guidelines, guidelines support ongoing } \\
\text { metabolic monitoring of children on } \\
\text { antipsychotics. }\end{array}$ \\
\hline
\end{tabular}

for identified beneficiaries. The 10 states were chosen on the basis of Mathematica Policy Research reports, which showed that these states provided adequate encounter/managed care data. ${ }^{32}$ Children and adolescents who were aged 1 to 20 years at the end of 2008 were included when there was evidence of an antipsychotic paid claim or encounter in 2008. A total of 144,200 children on antipsychotics met criteria for 1 or more of the draft metrics. This study was deemed exempt from review by the Institutional Review Boards of the New York State Psychiatric Institute and Rutgers University.

Eligibility categories identified in the last observed month in the cohort were collapsed into the following aid categories: SSI, foster care, income, and other aid categories. SSI disability is determined when a child has a physical or mental impairment that results in severe impairment that is expected to persist for a year or longer, as defined by Sec. 1614(a)(3)(C)(i) of the Social Security Act. Foster care is an element of the child welfare system where a child is placed in out-of-home care. Income-based eligibility is determined by the federal poverty level. The other aid category included state-specific eligibility determinations, specifically, children determined to be medically needy (when a state opts to provide Medicaid to individuals with high medical expenses whose income exceeds the threshold) and children with other state-specified eligible programs (e.g., families receiving up to 12 months of extended benefits or families who are not lawful permanent residents).

Medicaid eligibility is an important consideration to ensure that data is observable. We followed the continuous eligibility requirements for each measure, such that continuous eligibility was required for the time periods covered by each measure. Specifically, eligibility requirements ranged from 3 months to 120 days before the earliest prescription dispensing date for an antipsychotic through 30 days after (a total of 150 days of continuous enrollment), to 12 months with an allowable 1-month gap. The varying continuous eligibility requirements supported the creation of measures that were as sensitive as possible in order to identify all potential cases that could be observed.

Figure 1 provides the inclusion and exclusion criteria for each measure and the total sample size that was included in each analysis. While only 3 months of eligibility were 


\begin{tabular}{|c|c|c|c|c|c|c|c|c|c|c|}
\hline & \multicolumn{10}{|c|}{ Medicaid Eligibility Category } \\
\hline & \multicolumn{2}{|c|}{$\begin{array}{l}\text { Supplemental } \\
\text { Security Income }\end{array}$} & \multicolumn{2}{|c|}{ Foster Care } & \multicolumn{2}{|c|}{ Other Aid } & \multicolumn{2}{|c|}{ Income Aid } & \multicolumn{2}{|c|}{ Total } \\
\hline & $\mathrm{n}$ & $\%$ & $\mathbf{n}$ & $\%$ & $\mathrm{n}$ & $\%$ & $\mathrm{n}$ & $\%$ & $\mathrm{n}$ & $\%$ \\
\hline & 47,694 & 33.1 & 31,375 & 21.8 & 6,289 & 4.4 & 58,842 & 40.8 & 144,200 & 100.0 \\
\hline \multicolumn{11}{|l|}{ Age group } \\
\hline $0-5$ years $(\mathrm{SSI})$ & 1,290 & 2.7 & 792 & 2.5 & 167 & 2.7 & 2,338 & 4.0 & 4,587 & 3.2 \\
\hline $6-11$ years (foster care) & 13,722 & 28.8 & 9,000 & 28.7 & 1,452 & 23.1 & 22,126 & 37.6 & 46,300 & 32.1 \\
\hline 12-17 years (other aid) & 21,424 & 44.9 & 18,521 & 59.0 & 2,040 & 32.4 & 29,088 & 49.4 & 71,073 & 49.3 \\
\hline $18-20$ years (income aid) & 11,258 & 23.6 & 3,062 & 9.8 & 2,630 & 41.8 & 5,290 & 9.0 & 22,240 & 15.4 \\
\hline \multicolumn{11}{|l|}{ Gender } \\
\hline Female & 12,325 & 25.8 & 11,287 & 36.0 & 2,305 & 36.7 & 19,572 & 33.3 & 45,489 & 31.5 \\
\hline Male & 35,369 & 74.2 & 20,088 & 64.0 & 3,984 & 63.3 & 39,270 & 66.7 & 98,711 & 68.5 \\
\hline \multicolumn{11}{|l|}{ Race/ethnicity } \\
\hline Hispanic, any race & 5,321 & 11.2 & 2,838 & 9.0 & 1,152 & 18.3 & 5,955 & 10.1 & 15,266 & 10.6 \\
\hline White non-Hispanic & 21,249 & 44.6 & 18,879 & 60.2 & 3,805 & 60.5 & 41,814 & 71.1 & 85,747 & 59.5 \\
\hline Black non-Hispanic & 7,891 & 16.5 & 8,447 & 26.9 & 899 & 14.3 & 8,694 & 14.8 & 25,931 & 18.0 \\
\hline Other & 1,257 & 2.6 & 439 & 1.4 & 208 & 3.3 & 969 & 1.6 & 2,873 & 2.0 \\
\hline Unknown & 11,976 & 25.1 & 772 & 2.5 & 225 & 3.6 & 1,410 & 2.4 & 14,383 & 10.0 \\
\hline \multicolumn{11}{|l|}{ Diagnosis $^{a}$} \\
\hline $\begin{array}{l}\text { Consistent with antipsychotic } \\
\text { treatment }\end{array}$ & 27,624 & 57.9 & 14,021 & 44.7 & 3,309 & 52.6 & 25,895 & 44.0 & 70,849 & 49.1 \\
\hline Other & 20,070 & 42.1 & 17,354 & 55.3 & 2,980 & 47.4 & 32,947 & 56.0 & 73,351 & 50.9 \\
\hline \multicolumn{11}{|c|}{$\begin{array}{l}\text { Note: Chi-square tests determined that all comparisons were statistically significant, specifically age group by aid category }(X 2(9)=9,484, P<0.0001) ; \text { gender by aid } \\
\text { category (X2 (3) =1,159, P<0.0001); race by aid category (X2(12)=22,024, P<0.0001); and diagnosis by aid category (X2 }(3)=2,370, P<0.0001) \text {. } \\
\text { "For this covariate, those with an inpatient encounter or } 2 \text { outpatient encounters with a diagnosis consistent with a primary antipsychotic indication (schizophrenia } \\
\text { spectrum, bipolar disorder, tic disorders, autism, and major depression with psychotic behavior identified by the following ICD-9-CM codes } 295,296.0,296.1,296.4, \\
296.5,296.6,296.7,296.8,297,298,299,296.24,296.34, \text { and 307.2) were categorized as "1," and all other children without any of these diagnoses were defined as "0." } \\
\text { ICD-9-CM = International Classification of Diseases, Ninth Revision, Clinical Modification; SSI = Supplemental Security Income. }\end{array}$} \\
\hline
\end{tabular}

required to identify the 144,200 sample, almost $90 \%$ (89.26\%, $\mathrm{n}=128,714$ ) were continuously eligible for 10 months or longer, which suggests that, in general, the population of children on antipsychotics remained eligible for Medicaid during the year.

\section{Quality Measures for Antipsychotic Medication Management}

The NCINQ suite of quality measures for antipsychotic medication management is described in Table 1. The sample included 58,842 children with income-based Medicaid eligibility; 47,694 children receiving SSI; 31,375 children in foster care; and 6,289 children with other aid categories that had continuous eligibility for 3 or more months (Table 2). Description of the measures from Table 1 are as follows:

Use of High-than-Recommended Doses of Antipsychotics: the percentage of children and adolescents who received 2 or more antipsychotic medications with higher than recommended doses among those who received antipsychotics on at least 2 different dates during the measurement year. The hierarchy of decision rules to identify the maximum dose followed the New York State PSYCKES (Psychiatric Clinical Knowledge Enhancement System ${ }^{33}$ ) high-dose measure. In short, when there was a U.S. Food and Drug Administration
(FDA)-recommended maximum dose approved for use in a pediatric population, the maximum dose as specified in the Physicians' Desk Reference was used. ${ }^{34}$ When there were multiple indications for youth, the maximum dose for any psychiatric indication was used. When there was no FDA indication, the maximum dose specified in the Texas Department of Family \& Protective Services report "Psychotropic Medication Utilization Parameters for Children and Youth in Foster Care" (2013) was applied. ${ }^{35}$ If not addressed in either of these resources, the maximum dose listed in Appendix 1 of Pediatric Psychopharmacology: Principles and Practice (2011) was used. ${ }^{36}$ If not addressed in any these resources, the maximum dose for adults identified by the FDA as specified in the Physicians' Desk Reference was applied. Regarding weight-based doses, for ages 0-12 years, the maximum dose was based on a weight of $40 \mathrm{~kg}$. For ages 13-17 years, the maximum dose was based on a weight of $70 \mathrm{~kg}$

Use of Multiple Concurrent Antipsychotics: the percentage of children and adolescents on 2 or more antipsychotics concurrently for longer than 90 days at any point in the measurement year based on the New York State PSYCKES antipsychotic polypharmacy measure. ${ }^{30,33}$ Three months of continuous Medicaid eligibility was required. The antipsychotic medication trial 
start date was the first date that the medication was filled by the client during the period of observation (2008). The end date was the last date the prescription was picked up during the period of observation plus the days supply, allowing for a gap (32 days) in days supply between consecutive start and end dates of the same medication. This measure constructs individual antipsychotic medication trials and then sums the days that multiple, different agents were available to the child or adolescent.

Use of First-Line Psychosocial Care: the percentage of children and adolescents without a primary indication for antipsychotics who were newly prescribed an antipsychotic medication and had evidence of psychosocial care 90 days before through 30 days after starting the medication. During the study period, to be qualified as starting a new antipsychotic regimen, the recipient must have had no antipsychotic medication history 120 days before the earliest prescription dispensing date for an antipsychotic medication. Qualifying Current Procedural Terminology (CPT) and Healthcare Common Procedure Coding System (HCPCS) codes for psychosocial service were used (CPT codes: 90804 to 90815, 90845 to 90847, 90849, 90853, 90857, 90875, 90876 and 90880; HCPCS codes: H2017 to H2O2O, H0032, H0035 to H0040, H0045, H0046, H2OOl, and H2010 to H2013). A Medicaid continuous eligibility period of 120 days before the earliest prescription dispensing date for an antipsychotic through 30 days after the dispensing date was required. Exclusions included those with an inpatient encounter or 2 outpatient encounters with a diagnosis consistent with a primary antipsychotic indication (schizophrenia spectrum, bipolar disorder, tic disorders, autism, and major depression with psychotic behavior identified by the following International Classification of Diseases, Ninth Revision, Clinical Modification [ICD-9-CM] codes: 295, 296.0, 296.1, 296.4, 296.5, 296.6, 296.7, 296.8, 297, 298, 299, 296.24, 296.34, and 307.2).

Follow-up Visit: children and adolescents with a newly prescribed antipsychotic medication who had 1 or more follow-up visits with a prescriber within 30 days after the new prescription was dispensed among those newly started on an antipsychotic. New antipsychotic regimens were defined the same way as in the Use of First-Line Psychosocial Care measure. Follow-up care visits were defined using CPT and HCPC codes and included primary care and behavioral health visits. A Medicaid continuous eligibility period of 120 days before the earliest prescription dispensing date for an antipsychotic through 30 days after was required. Recipients with an acute inpatient encounter for mental health or chemical dependency during the 30 days after the earliest prescription dispensing date for an antipsychotic were also excluded.

Metabolic Screening: the percentage of children and adolescents aged under 21 years and newly prescribed an antipsychotic medication who had baseline metabolic screening within 90 days before 15 days after the initiation of the antipsychotic. New antipsychotic regimens were defined as no antipsychotic medication history 120 days before the earliest prescription dispensing date for an antipsychotic prescription during the study period. A Medicaid continuous eligibility period of 120 days before the earliest prescription dispensing date for an antipsychotic through 30 days after was required. Metabolic screening required a blood glucose test and blood lipids test. Blood glucose test was defined as 1 or more tests for hemoglobin Alc (Alc) for those with diabetes or blood glucose/ Alc test for those without diabetes. The CPT codes used to define an Alc test were 83036, 83037, and 3044F to 3046F. A glucose test was defined as claims with the following CPT codes: 80047, 80048, 80050, 80053, 80069, 82947, 82950, and 82951. The following CPT codes identified a lipid test: 80061, 82465, 83700, 83701, 83704, 83715, 83716, 83721, 84478 , and $3048 \mathrm{~F}$ to $3050 \mathrm{~F}$.

Metabolic Monitoring: the proportion of children and adolescents aged under 21 years, with 2 or more antipsychotic prescriptions on different days, who had metabolic testing at any time during the measurement year. A continuous Medicaid eligibility of 12 months was required with an allowable 1-month gap. The monitoring tests required a blood glucose test and a blood lipids test, and tests were defined in the same way as the Metabolic Screening measure.

\section{Data Analysis}

For data analysis, statistical software SAS 9.2 or 9.4 was used (SAS Institute, Cary, NC). In order to identify disparities and assess measure performance, proportions were also calculated by age, race/ethnicity, and diagnosis consistent with antipsychotic use. Each measure proportion, including ClopperPearson confidence limits, was calculated for SSI, foster care, and income-based and other aid populations. Logistic regression was used to calculate the relative differences in proportions for SSI, foster care, and other aid categories compared with income-based eligible children. To control for differences across the eligibility categories, models adjusting for age, gender, race/ethnicity, and diagnosis were also reported. The diagnosis was defined as a binary variable to identify those children with a diagnosis consistent with first-line use of an antipsychotic, with "1" indicating those with an inpatient encounter or 2 outpatient encounters with a diagnosis consistent with a primary antipsychotic indication (schizophrenia spectrum, bipolar disorder, tic disorders, autism, and major depression with psychotic behavior identified by ICD-9-CM codes 295, 296.0, 296.1, 296.4, 296.5, 296.6, 296.7, 296.8, 297, 298, 299, 296.24, 296.34, and 307.2). All other children without 1 of these diagnoses were defined as "0."

Diagnosis was not included as a covariate in the analysis of the Use of First-Line Psychosocial Care measure, since children with these diagnoses were excluded, by definition, from the measure. Diagnosis was also not included as a covariate in the analysis for the management measures (Table 1), since appropriate follow-up and metabolic 


\section{TABLE 3 Quality of Antipsychotic Medication Management by Medicaid Aid Category ${ }^{\text {a }}$}

\begin{tabular}{|c|c|c|c|c|c|c|}
\hline $\begin{array}{l}\text { Quality Measure and } \\
\text { Aid Category }\end{array}$ & Total & Numerator & $\%$ & OR & $\mathrm{AOR}^{\mathrm{b}}$ & $95 \%$ CI \\
\hline \multicolumn{7}{|c|}{ Use of Higher-than-Recommended Doses ${ }^{c}$} \\
\hline SSI & 45,381 & 5,130 & 11.3 & 2.50 & 2.44 & $2.32-2.58$ \\
\hline Foster care & 30,396 & 3,150 & 10.4 & 2.26 & 2.49 & $2.35-2.63$ \\
\hline Other aid & 5,606 & 238 & 4.2 & 0.87 & 1.03 & $0.90-1.18$ \\
\hline Income aid & 54,155 & 2,632 & 4.9 & Referent & & \\
\hline \multicolumn{7}{|c|}{ Use of Multiple Concurrent Antipsychotics ${ }^{c}$} \\
\hline SSI & 36,122 & 3,221 & 8.9 & 2.68 & 2.22 & $2.07-2.38$ \\
\hline Foster care & 25,089 & 1,974 & 7.9 & 2.33 & 2.20 & $2.04-2.36$ \\
\hline Other aid & 3,517 & 154 & 4.4 & 1.25 & 0.97 & $0.82-1.16$ \\
\hline Income aid & 37,129 & 1,311 & 3.5 & Referent & & \\
\hline \multicolumn{7}{|c|}{ Use of First-Line Psychosocial Cared } \\
\hline SSI & 2,897 & 1,415 & 48.8 & 1.34 & 1.39 & $1.27-1.53$ \\
\hline Foster care & 2,303 & 1,307 & 56.8 & 1.85 & 1.83 & $1.67-2.01$ \\
\hline Other aid & 600 & 277 & 46.2 & 1.21 & 1.32 & $1.12-1.57$ \\
\hline Income aid & 8,798 & 3,654 & 41.5 & Referent & & \\
\hline \multicolumn{7}{|c|}{ Follow-up Visit After Initiation of Antipsychotics ${ }^{d}$} \\
\hline SSI & 6,664 & 4,598 & 69.0 & 0.96 & 0.96 & $0.90-1.03$ \\
\hline Foster care & 4,182 & 3,038 & 72.6 & 1.14 & 1.18 & $1.10-1.28$ \\
\hline Other aid & 1,231 & 861 & 69.9 & 1.00 & 1.04 & $0.91-1.18$ \\
\hline Income aid & 16,539 & 11,568 & 69.9 & Referent & & \\
\hline \multicolumn{7}{|c|}{ Metabolic Screening for Children and Adolescents Newly on Antipsychotics } \\
\hline SSI & 10,044 & 626 & 6.2 & 1.02 & 0.97 & $0.87-1.08$ \\
\hline Foster care & 6,447 & 535 & 8.3 & 1.39 & 1.37 & $1.23-1.53$ \\
\hline Other aid & 2,183 & 196 & 9.0 & 1.51 & 1.29 & $1.09-1.52$ \\
\hline Income aid & 19,716 & 1,208 & 6.1 & Referent & & \\
\hline \multicolumn{7}{|c|}{ Metabolic Monitoring for Children and Adolescents on Antipsychotics } \\
\hline SSI & 42,555 & 8,953 & 21.0 & 1.23 & 1.16 & $1.12-1.20$ \\
\hline Foster care & 27,630 & 6,941 & 25.1 & 1.55 & 1.49 & $1.44-1.55$ \\
\hline Other aid & 4,138 & 890 & 21.5 & 1.27 & 1.08 & $1.00-1.17$ \\
\hline Income aid & 46,048 & 8,181 & 17.8 & Referent & & \\
\hline \multicolumn{7}{|c|}{$\begin{array}{l}{ }^{a} \mathrm{~N}=10 \text { states, } 2008 \text { Medicaid Analytic Extract data. } \\
{ }^{b} \text { Adjusted models included age, gender, and racelethnicity. } \\
{ }^{F} \text { For higher-than-recommended dose and multiple concurrent use, a fourth covariate indicating whether the recipient had a diagnosis consistent with receiving an } \\
\text { antipsychotic was included. } \\
{ }^{T} \text { Two states with low use of the identified CPT codes were excluded from these measures on the assumption that these services were not observable for these states. } \\
\text { AOR = adjusted odds ratio; CI= confidence interval; CPT=Current Procedural Terminology; OR=odds ratio; SSI = Supplemental Security Income. }\end{array}$} \\
\hline
\end{tabular}

screening and monitoring are important regardless of the reason why the antipsychotic was prescribed. Two states were observed to have substantially small amounts of outpatient mental health care (as identified by the lack of the CPT/HCPCS codes observable in the data). Because these services may not have been observable in MAX data, these 2 states were excluded from the reported analyses of the Use of FirstLine Psychosocial Care and Follow-up Visit measures.

\section{Results}

\section{Appropriate Use of Antipsychotic Measures}

Compared with children eligible for income-based Medicaid, children receiving SSI or in foster care were twice as likely to receive higher-than-recommended antipsychotic doses
(SSI: $11.4 \%$ vs. $4.9 \%$, adjusted odds ratio $[\mathrm{AOR}]=2.44,95 \%$ confidence interval $[\mathrm{CI}]=2.32-2.58$; foster care: $10.4 \%$ vs. $4.9 \%$, $\mathrm{AOR}=2.5,95 \% \mathrm{CI}=2.4-2.6)$ and multiple concurrent antipsychotics (SSI: $8.9 \%$ vs. $3.5 \%, \mathrm{AOR}=2.22,95 \% \mathrm{CI}=2.07-2.38$; foster care: $7.9 \%$ vs. $3.5 \%, \mathrm{AOR}=2.3,95 \% \mathrm{CI}=2.0-2.4$; Table 3). These relationships persisted after controlling for age, gender, race/ethnicity, and mental health diagnosis with a primary indication for antipsychotic treatment.

\section{Management of Youth on Antipsychotic Measures}

Children receiving SSI were as likely as children eligible for income-based Medicaid to receive a follow-up visit after initiation of an antipsychotic but were more likely to have had a psychosocial visit before starting an antipsychotic (48.8\% vs. $41.5 \%, \mathrm{AOR}=1.39,95 \% \mathrm{CI}=1.27-1.53$; Table 3 ). Access to 
services supporting appropriate management of antipsychotic medications was also more common among foster care children compared with children eligible for Medicaid due to poverty. Children in foster care initiating antipsychotic treatment were substantially more likely to have had a psychosocial service (56.8\% vs. $41.5 \%$, odds ratio $[\mathrm{OR}]=1.85,95 \% \mathrm{CI}=1.68-2.03)$ and modestly but significantly more likely to have a followup visit with a prescriber $(72.6 \%$ vs. $69.9 \%, \mathrm{OR}=1.14,95 \%$ $\mathrm{CI}=1.06-1.23)$. These relationships persisted after controlling for age, gender, and race/ethnicity.

Glucose and lipid baseline screening and ongoing monitoring for the metabolic effects of antipsychotic medications were infrequent or rare among all children but more common in the foster care group than in children with income-based Medicaid aid. Just over $8 \%$ of children in foster care on antipsychotics had evidence of a baseline metabolic screen for glucose and lipid profiles, and $25.1 \%$ had evidence of at least annual laboratory monitoring. These differences were significant, even after controlling for other factors $(\mathrm{AOR}=1.37,95 \% \mathrm{CI}=1.23-1.53$ for screening; $\mathrm{AOR}=1.49,95 \% \mathrm{CI}=1.44-1.55$ for monitoring). Children with SSI eligibility were also more likely than children in poverty to receive annual monitoring (AOR $=1.16,95 \%$ $\mathrm{CI}=1.12-1.20$; Table 3).

\section{Discussion}

While indicators of overuse were more common among children receiving SSI and in foster care, access to follow-up, metabolic monitoring, and psychosocial services was somewhat better in these groups. However, substantial quality shortfalls existed for all groups, particularly use of psychosocial care and metabolic monitoring. Our results support earlier work indicating that children in foster care are at increased risk of receiving multiple concurrent antipsychotics, and this trend may be increasing. ${ }^{8,9,24}$ Also our results show that children in foster care are more likely to have higher-than-recommended doses of antipsychotics when compared with children with income-related Medicaid eligibility. In addition, this study identifies children and adolescents with SSI as also being at higher risk of receiving high doses and multiple concurrent antipsychotics, after adjusting for diagnosis, than children with income-based eligibility. This finding is consistent with earlier work that found that foster and disabled populations were comparable with regard to mental health conditions and services provided. ${ }^{37}$

Although the study results show that children in foster care on antipsychotics were more likely to have worse rates on overuse measures, they were also more likely to have better access to services. While this is encouraging, the use of psychosocial interventions was less than ideal in both populations, with only $56.8 \%$ of foster care youth and $41.5 \%$ of youth eligible for Medicaid based on income receiving psychosocial intervention as first-line treatment. So, a large proportion of children in the absence of a diagnostic indication did not receive firstline psychosocial services before beginning an antipsychotic.
Our results are consistent with earlier reports of concerning antipsychotic prescribing practices for children in foster care, ${ }^{8,24}$ and our research sheds new light on the lack of use of recommended services for publicly insured children receiving antipsychotic medications.

Given the metabolic concerns associated with antipsychotic use and the fact that children may be more susceptible to the metabolic consequences of antipsychotics, ${ }^{22,38,39}$ screening and monitoring for both populations were disappointingly low. This finding is consistent with other literature, ${ }^{17,18}$ indicating a gap in care for all children on antipsychotic medications. This study's findings that children in foster care were more likely to get a baseline screening and ongoing monitoring suggest that providers working with these children may be more aware of the metabolic concerns of these medications. However, only $25 \%$ of these children received both glucose and lipid monitoring. In addition, understanding how adherence and compliance to antipsychotics may influence the metabolic measures is an important consideration for future studies. Finally, a previous study indicates that the prevalence of some quality measures will vary by prescriber. ${ }^{40}$ This investigation did not evaluate the distribution of any of these quality concerns at the prescriber level, which would be important future work.

\section{Limitations}

There are several limitations to this study that need to be considered. The analyses in this study focused on children and adolescents using antipsychotics in 10 state Medicaid populations and may not apply more broadly to other populations of children. Also, because state payment methods for care and the full prescription/medical benefits packages may not always be observable in the claims data, the rates of follow-up and psychosocial services may be underestimated. Further, understanding how state benefits vary across aid categories could shed important light on some of the variation seen in this work. Finally, while we did control for any diagnosis with a first-line indication for an antipsychotic to account for the possibility that children with such diagnoses may be more likely to experience the overuse measures, the analyses did not otherwise adjust for severity of the children's clinical conditions, psychosocial settings, or health literacy differences that may be observed across these aid categories.

\section{Conclusions}

Results of this study highlight substantial gaps in performance on quality measures for care processes related to safe and judicious antipsychotic use among all children eligible for Medicaid. Foster care children were twice as likely to have higher doses and multiple concurrent use of antipsychotics, but they had somewhat better access to follow-up, metabolic monitoring, and psychosocial services than other children using antipsychotics who were eligible for Medicaid. Despite the decreasing trend of antipsychotic use among children, metrics 
indicate ongoing quality issues. Policies supporting the use of psychosocial care over the use of antipsychotics are needed, as well as policies that encourage metabolic screening of children newly placed on antipsychotics and ongoing monitoring for those with extended use. These metrics provide an important opportunity to support these quality initiatives.

As of 2016, three of the measures related to multiple concurrent antipsychotics, metabolic monitoring, and use of psychosocial services for children newly starting antipsychotics were formally adopted by the National Committee for Quality Assurance for national Healthcare Effectiveness Data and Information Set (HEDIS) reporting. Monitoring by managed care organizations should support quality initiatives to improve the performance of these measures and ultimately improve the care provided to children and adolescents who have been prescribed antipsychotics. In fact, recent work suggests that children with attention-deficit/hyperactivity disorder may be receiving treatment that adheres more closely to clinical practice standards as evidenced by increasing proportions of combined psychotherapy and medication, increases in therapy alone, and decreases in medication alone. ${ }^{41}$ Although these quality improvements may be the result of several factors, it is noteworthy that these measures of pediatric care have been a HEDIS metric for children with attention-deficit/hyperactivity disorder for many years. Therefore, it is likely that systematic monitoring and accountability played a role in changing clinical practice. Our findings further demonstrate the importance of ongoing quality monitoring and direct efforts to improve antipsychotic prescription-related care processes among Medicaid youth.

\section{Authors}

EMILY LECKMAN-WESTIN, PhD, New York State Office of Mental Health, Albany, New York, and State University of New York at Albany, School of Public Health, Rensselaer, New York. MOLLY FINNERTY, MD, New York State Office of Mental Health, and New York University Langone Health, New York, New York. SARAH HUDSON SCHOLLE, MPH, DrPH; SEPHEEN BYRON, MHS; and EMILY MORDEN, MSW, National Committee for Quality Assurance, Washington, DC. RITI PRITAM, MA, MRP; DEBORAH LAYMAN, MA; and EDITH KEALEY, PhD, New York State Office of Mental Health, Albany, New York. SHEREE NEESE-TODD, MA; SCOTT BILDER, PhD; and STEPHEN CRYSTAL, PhD, Rutgers University, New Brunswick, New Jersey. SARAH HORWITZ, PhD, and KIMBERLY HOAGWOOD, PhD, New York University Langone Health, New York, New York.

AUTHOR CORRESPONDENCE: Emily Leckman-Westin, PhD, New York State Office of Mental Health, 44 Holland Ave., Albany NY 12208. Tel.: 518.549.5183; E-mail: Emily.leckman-westin@omh.ny.gov.

\section{DISCLOSURES}

This project was supported by grant number U18HS020503 from the Agency for Healthcare Research and Quality (AHRQ) and Centers for Medicare \& Medicaid Services (CMS). Additional support for Rutgers-based participants was provided from AHRQ grants R18 HS019937 and U19HS021112, as well as the New York State Office of Mental Health. The content of this study is solely the responsibility of the authors and does not necessarily represent the official views of AHRQ, CMS, or the New York State Office of Mental Health.

Finnerty has been the principle investigator on research grants/contracts from Bristol Myers Squibb and Sunovion, but her time on these projects is fully supported by the New York State Office of Mental Health. Scholle, Byron, and Morden work for the National Committee for Quality Assurance, a notfor-profit organization that develops and maintains quality measures. NeeseTodd was at Rutgers University at the time of this study and is now employed by the National Committee for Quality Assurance. The other authors have no financial relationships relevant to this article to disclose.

Study concept and design were contributed by Finnerty, Neese-Todd, and Crystal, assisted by Scholle, Leckman-Westin, Horowitz, and Hoagwood. Scholle, Byron, Morden, and Hoagwood collected the data, and data interpretation was performed by Pritam, Bilder, Leckman-Westin, and Finnerty, with assistance from Scholle, Byron, Crystal, Kealey, and Neese-Todd. The manuscript was written by Leckman-Westin, Kealey, and Horowitz and revised by Layman, Crystal, Leckman-Westin, Finnerty, Scholle, Neese-Todd, and Horowitz, along with the other authors.

\section{ACKNOWLEDGMENTS}

The authors thank Kelly Kelleher, PhD, and James F. Leckman, PhD, for their review of earlier versions of this manuscript and Jeffrey Wilhite, MPH, for his assistance during the final revision.

\section{REFERENCES}

1. Olfson M, King M, Schoenbaum M. Treatment of young people with antipsychotic medications in the United States. JAMA Psychiatry. 2015;72(9):867-74.

2. Edelsohn GA, Karpov I, Parthasarathy M, et al. Trends in antipsychotic prescribing in medicaid-eligible youth. J Am Acad Child Adolesc Psychiatry. 2017;56(1):59-66

3. Aparasu RR, Bhatara V, Gupta S. U.S. national trends in the use of antipsychotics during office visits, 1998-2002. Ann Clin Psychiatry. 2005;17(3):147-52

4. Birnbaum ML, Saito E, Gerhard T, et al. Pharmacoepidemiology of antipsychotic use in youth with ADHD: trends and clinical implications. Curr Psychiatry Rep. 2013;15(8):382.

5. Cooper WO, Arbogast PG, Ding H, Hickson GB, Fuchs DC, Ray WA Trends in prescribing of antipsychotic medications for U.S. children. Ambul Pediatr. 2006;6(2):79-83.

6. Harrison JN, Cluxton-Keller F, Gross D. Antipsychotic medication prescribing trends in children and adolescents. J Pediatr Heal Care. 2012;26(2):139-45.

7. Matone M, Localio R, Huang YS, Dosreis S, Feudtner C, Rubin D. The relationship between mental health diagnosis and treatment with secondgeneration antipsychotics over time: a national study of U.S. Medicaidenrolled children. Health Serv Res. 2012;47(5):1836-60

8. Zito JM, Burcu M, Ibe A, Safer DJ, Magder LS. Antipsychotic use by Medicaid-insured youths: impact of eligibility and psychiatric diagnosis across a decade. Psychiatr Serv. 2013;64(3):223-29.

9. Kreider AR, Matone M, Bellonci C, et al. Growth in the concurrent use of antipsychotics with other psychotropic medications in Medicaid-enrolled children. J Am Acad Child Adolesc Psychiatry. 2014;53(9):960-70.e2.

10. Rubin D, Matone M, Huang YS, DosReis S, Feudtner C, Localio R. Interstate variation in trends of psychotropic medication use among Medicaid-enrolled children in foster care. Child Youth Serv Rev. 2012;34(8):1492-99. 
11. Maher AR, Theodore G. Summary of the comparative effectiveness review on off-label use of atypical antipsychotics. J Manag Care Pharm. 2012;18(5 Suppl B):S1-20. Available at: https://www.jmcp.org/doi/ abs/10.18553/jmcp.2012.18.s5-b.1.

12. Leslie DL, Rosenheck R. Off-label use of antipsychotic medications in Medicaid. Am J Manag Care. 2012;18(3):109-17.

13. Pappadopulos E, Rosato NS, Correll CU, et al. Experts' recommendations for treating maladaptive aggression in youth. J Child Adolesc Psychopharmacol. 2011;21(6):505-15.

14. Linares LO, Martinez-Martin N, Castellanos FX. Stimulant and atypical antipsychotic medications for children placed in foster homes. PLoS One. 2013;8(1):e54152.

15. Vanderwerker L, Akincigil A, Olfson M, Gerhard T, Neese-Todd S, Crystal S. Foster care, externalizing disorders, and antipsychotic use among Medicaid-enrolled youths. Psychiatr Serv. 2014;65(10):1281-84.

16. Finnerty MT, Neese-Todd S, Pritam R, et al. Access to psychosocial services prior to starting antipsychotic treatment among Medicaid-insured youth. J Am Acad Child Adolesc Psychiatry. 2016;55(1):69-76.

17. Morrato EH, Druss B, Hartung DM, et al. Metabolic testing rates in 3 state Medicaid programs after FDA warnings and ADA/APA recommendations for second-generation antipsychotic drugs. Arch Gen Psychiatry. 2010;67(1):17-24

18. Raebel MA, Penfold R, McMahon AW, et al. Adherence to guidelines for glucose assessment in starting second-generation antipsychotics. Pediatrics. 2014;134(5):e1308-14.

19. Rubin DM, Kreider AR, Matone M, et al. Risk for incident diabetes mellitus following initiation of second-generation antipsychotics among Medicaid-enrolled youths. JAMA Pediatr. 2015;169(4):e150285.

20. Baeza I, Vigo L, de la Serna E, et al. The effects of antipsychotics on weight gain, weight-related hormones and homocysteine in children and adolescents: a l-year follow-up study. Eur Child Adolesc Psychiatry. 2016;26(1):1-12.

21. Arango C, Giraldez M, Merchan-Naranjo J, et al. Second-generation antipsychotic use in children and adolescents: a six-month prospective cohort study in drug-naive patients. J Am Acad Child Adolesc Psychiatry. 2014;53(11):1179-90.e4.

22. De Hert M, Detraux J, van Winkel R, Yu W, Correll CU. Metabolic and cardiovascular adverse effects associated with antipsychotic drugs. Nat Rev Endocrinol. 2012;8(2):114-26.

23. Edelsohn GA, Parthasarathy M, Terhorst L, Karpov I, Schuster J. Measurement of metabolic monitoring in youth and adult Medicaid recipients prescribed antipsychotics. J Manag Care Spec Pharm. 2015;21(9):769-77. Available at: https://www.jmcp.org/doi/10.18553/jmcp.2015.21.9.769.

24. DosReis S, Yoon Y, Rubin DM, Riddle MA, Noll E, Rothbard A. Antipsychotic treatment among youth in foster care. Pediatrics. 2011;128(6):e1459-66.

25. Finnerty M, Neese-Todd S, Scott Bilder M, Olfson M, Stephen Crystal M. MEDNET: a multistate policy maker-researcher collaboration to improve prescribing practices. Psychiatr Serv. 2014;65(11):1297-99.

26. Muller L, O'Hara B, Kearney J. Trends in the Social Security and Supplemental Security Income Disability programs. SSA Publication No. 13-11831. August 2006. Available at: https://www.ssa.gov/policy/docs/chartbooks/disability_trends/index.html. Accessed January 25, 2018.
27. Boat TF, Buka SL, Perrin JM. Children with mental disorders who receive disability benefits: a report from the IOM. JAMA. 2015;314(19):2019-20.

28. Perrin JM, Houtrow A, Kelleher K, et al. Supplemental Security Income benefits for mental disorders. Pediatrics. 2016;138(1):207-18.

29. Byron SC, Gardner W, Kleinman LC, et al. Developing measures for pediatric quality: methods and experiences of the CHIPRA pediatric quality measures program grantees. Acad Pediatr. 2014;14(5 Suppl):S27-32.

30. Leckman-Westin E, Kealey E, Gupta N, et al. Validation of a claimsbased antipsychotic polypharmacy measure. Pharmacoepidemiol Drug Saf. 2014;23(6):628-35.

31. Kealey E, Scholle SH, Byron SC, et al. Quality concerns in antipsychotic prescribing for youth: a review of treatment guidelines. Acad Pediatr. 2014;14(5 Suppl):S68-75.

32. Byrd VLH, Dodd AH. Assessing the usability of encounter data for enrollees in comprehensive managed care across MAX 2007-2009. MAX Medicaid Policy Brief 15. December 2012. Available at: https://www.cms. gov/Research-Statistics-Data-and-Systems/Computer-Data-and-Systems/ MedicaidDataSourcesGenInfo/Downloads/MAX_IB_15_AssessingUsability. pdf. Accessed January 25, 2018.

33. New York State. Office of Mental Health. About PSYCKES. 2017. Available at: https://www.omh.ny.gov/omhweb/psyckes_medicaid/about/. Accessed January 25, 2018.

34. Physicians' Desk Reference. 67th ed. Montvale, NJ: PDR Network; 2013

35. Texas Department of Family and Protective Services, University of Texas at Austin College of Pharmacy. Psychotropic medication utilization parameters for children and youth in foster care. September 2013. Available at: https://www.dfps.state.tx.us/Child_Protection/Medical_Services/documents/ reports/2013-09_Psychotropic_Medication_Utilization_Parameters_for_ Foster_Children.pdf. Accessed February 5, 2018.

36. Martin A, Scahill L, Charney D, Leckman J, eds. Pediatric Psychopharmacology: Principles \& Practice. New York: Oxford University Press; 2003

37. Harman J, Childs G, Kelleher K. Mental health care utilization and expenditures by children in foster care. Arch Pediatr Adolesc Med. 2000;154:1114-17.

38. Correll CU, Manu P, Olshanskiy V, Napolitano B, Kane JM, Malhotra AK. Cardiometabolic risk of second-generation antipsychotic medications during first-time use in children and adolescents. JAMA. 2009;302(16):1765-73.

39. Correll CU. Weight gain and metabolic effects of mood stabilizers and antipsychotics in pediatric bipolar disorder: a systematic review and pooled analysis of short-term trials. J Am Acad Child Adolesc Psychiatry. 2007;46(6):687-700.

40. Patel A, Medhekar R, Ochoa-Perez M, et al. Care provision and prescribing practices of physicians treating children and adolescents with ADHD Psychiatr Serv. 2017;68(7):681-88.

41. Hoagwood KE, Kelleher K, Zima BT, Perrin JM, Bilder S, Crystal S. Ten-year trends in treatment services for children with attention deficit hyperactivity disorder enrolled in Medicaid. Health Aff (Millwood). 2016;35(7):1266-70 